\title{
LABORATORY STUDY ON THE INFLUENCE OF CASTING ON PROPERTIES OF ULTRA-HIGH PERFORMANCE FIBRE REINFORCED CONCRETE (UHPFRC) SPECIMENS
}

\author{
Adam ZOFKA $^{\mathrm{a}}$, Migle PALIUKAITE் ${ }^{\mathrm{b}}$, Audrius VAITKUS ${ }^{\mathrm{b}}$, Dominika MALISZEWSKA ${ }^{\mathrm{a}}$, \\ Ramandeep JOSEN ${ }^{\mathrm{c}}$, Alexander BERNIER ${ }^{\mathrm{d}}$ \\ ${ }^{a}$ Road and Bridge Research Institute (IBDiM), ul. Instytutowa 1, 03-302 Warsaw, Poland \\ ${ }^{b}$ Road Research Institute, Vilnius Gediminas Technical University, Linkmenu g. 28, \\ 08217 Vilnius, Lithuania \\ ${ }^{c}$ Fay, Spofford \& Thorndike, Inc., 5 Burlington Woods Dr, Burlington, MA 01803, USA \\ ${ }^{d}$ Stantec Consulting, 261 Fifth Ave. 23rd Floor, New York, 10016, USA
}

Received 07 Nov 2013; accepted 02 Apr 2014

\begin{abstract}
This paper presents a study on the effects of casting procedure and resulting fibre orientation on the properties of Ultra-High Performance Fibre Reinforced Concrete (UHPFRC). To investigate the impact of fibre orientation in the UHPFRC specimens, three approaches were employed. First, densities were measured from the top, middle and bottom zones of the cylinders to observe physical changes as the function of cylinder height. Secondly, two engineering fracture tests were performed in both compression and tension, and a comparison of fracture energies was conducted between different cylinder zones. While previous studies have explored the influence of steel fibres on the UHPFRC performance, the Semi-Circular Bending (SCB) and Disc Compact Tension (DCT) experimental setups have not yet been used in the UHPFRC fracture testing. Lastly, samples from different zones were scanned using X-ray computer tomography (X-ray $\mathrm{CT}$ ). Both visual and digital image analysis of the X-ray scans were conducted in order to observe fibre orientation pattern changes within different zones. Although density calculations showed insignificant differences between different zones, fracture testing exhibited significant differences through the testing process as well as through fracture energy computations. Furthermore, X-ray CT demonstrated considerable differences in spatial fibre orientation with respect to two uniquely defined angles.
\end{abstract}

Keywords: ultra-high performance fibre reinforced concrete (UHPC), fracture properties, fibre orientation, X-ray computer tomography (X-ray CT).

Reference to this paper should be made as follows: Zofka, A.; Paliukaite, M.; Vaitkus, A.; Maliszewska, D.; Josen, R.; Bernier, A. 2014. Laboratory study on the influence of casting on properties of ultra-high performance fibre reinforced concrete (UHPFRC) specimens, Journal of Civil Engineering and Management 20(3): 380-388.

http://dx.doi.org/10.3846/13923730.2014.913680

\section{Introduction}

The high compressive strength as well as its relatively low cost and versatile construction applications have made concrete one of the most widely used structural materials of our time. However, its inadequacies in tension limit and its use leave it susceptible to unpredicted failures. Recent studies on Ultra-High Performance Concrete (UHPC) have shown significant improvement in mechanical properties including compressive and tensile strength (Graybeal 2006; Graybeal et al. 2003). Research performed on Fibre Reinforced Concrete (FRC) has also shown higher levels of tensile strength, along with a higher resistance to cracking due in large part to the inclusion of fibres (Zollo 1997). The combination of UHPC and FRC resulted in Ultra-High Performance Fibre Reinforced Concrete (UHPFRC), which consists of a very dense matrix with high quantities of fibre reinforcement
(Graybeal 2007; Gribniak et al. 2011; Corinaldesi, Moriconi 2012; Islam et al. 2012). With research efforts across the world currently focused on UHPFRC, it is vital to find the optimal method to cast UHPFRC samples and elements in the laboratory and in the pre-cast facility in order to maximize the use of the fibre reinforcement and to achieve desirable effects.

For the last 30 years, Fibre Reinforced Concrete has been a major focus for many researchers aiming to maximize mechanical properties. Research began by improving mechanical properties of the concrete with the addition of randomly dispersed fibres. Studies on fibre addition showed a significant improvement in flexural tensile strength of concrete as well as post-peak tensile softening (ductility) (Barris et al. 2012). Other studies investigated the effect of different fibre properties - fibre content, length, material types, spatial orientation, and shape - on concrete performance (Kang et al. 2011; 
Vejmelková et al. 2010; Kim et al. 2011; Hassan et al. 2012; Grinys et al. 2013; Pajak et al. 2013). The results of these studies have shown that flexural tensile strength of UHPFRC increases linearly with respect to the fibre volume ratio from $0 \%$ to $5 \%$, and that strength parameters are also linearly dependent on fibre content (Kang et al. 2011). Fibre types were investigated at low volume by Yao et al. (2003), who found that carbon-steel hybrid fibres give concrete the highest strength and flexural toughness. Modifications of fibres by physically shaping them to create a better mechanical bond and to enhance ductility have also been researched. By enhancing fibre parameters, Wille et al. (2010) found that a deformed fibre volume of only $1.5 \%$ can result in a tensile strength of $13 \mathrm{MPa}[1.89 \mathrm{ksi}]$ and a strain-capacity improved from $0.3 \%$ to $0.6 \%$ compared to straight steel fibres.

Orientation and distribution of fibres are considered the biggest contributors to maximizing tensile strength in UHPFRC (Ferrara et al. 2011; Kang et al. 2011; Dai et al. 2012). There are several variables that affect both the orientation and distribution of fibres when casting UHPFRC specimens: amount, size and shape of fibres, workability of the matrix, method of compaction, as well as specimen size and shape (i.e. mould shape). Altering any one of these variables can distribute and orient the fibres differently. For example, an excessive amount of fibres would cause fibres to interact with each other and disallow proper distribution. If there is too much workability or if the compaction process is too long, then the fibres will settle and orient themselves horizontally. Different casting moulds will distort fibres differently and, therefore, tensile strengths will differ for the same UHPFRC material (Chanvillard, Rigaud 2003). There is a direct positive correlation between the number of fibres parallel to the tensile force and the strength of the specimen (Lee, Kim 2010), making this the main goal when casting fibre-reinforced specimens. Even the location within the mould, at which the matrix is poured in, has an effect of how fibres are oriented due to the direction of flow. Barnett et al. (2010) found that fibres tend to align perpendicular to the direction of flow, making the centre the best location to pour the matrix into moulds. Perfecting and understanding how to properly distribute and orient fibres during laboratory casting will allow for a smoother transition when preparing larger structural elements in pre-cast facilities or directly on a construction site.

This study focuses on comprehending the effects of the UHPFRC cylinder casting on fibre distribution and orientation by employing three distinct approaches: density measurements, engineering fracture testing and X-ray CT.

\section{Materials and methods}

\subsection{Materials}

In this study, samples were prepared from a special UHPFRC manufactured by Lafarge. This material consists of premix, water, steel fibres, polypropylene fibres and a high-range water-reducing admixture (HRWA). The premix consists of Portland cement, silica fume, ground quartz and fine sand. The hybrid high-carbon fibres are ranging in length from 13 to $15 \mathrm{~mm}$ [.511 to $.590 \mathrm{in}$.] with a diameter of $0.2 \mathrm{~mm}$ [.008 in.] and have concentration of $2 \%$ by volume within the UHPFRC. A breakdown of other components is shown in Table 1, which follows the mixture recipe recommended by the producer.

Table 1. Composition of UHPFRC mix

\begin{tabular}{l|c|c}
\hline \multicolumn{1}{c|}{ Material } & $\begin{array}{c}\text { Amount } \\
\mathrm{kg} / \mathrm{m}^{3}(\mathrm{lbs} / \mathrm{yd} 3)\end{array}$ & \% by weight \\
\hline Premix & $2198(3705)$ & 86.5 \\
\hline $\begin{array}{l}\text { Super-plasticizer } \\
\text { (HRWA) }\end{array}$ & $30.0(50.6)$ & 1.18 \\
\hline Accelerator & $30.0(50.6)$ & 1.18 \\
\hline Steel fibres & $151(253)$ & 5.91 \\
\hline Polypropylene fibres & $5.02(8.46)$ & 0.20 \\
\hline Water & $129(217)$ & 5.03 \\
\hline
\end{tabular}

The total of six $150 \mathrm{~mm}$ [5.90 in.] UHPFRC cylinders were prepared from the mix shown in Table 1, containing a water to cement ratio of 0.18 . The mixing procedure was based on the producer recommendations, with some minor adjustments due to the conditions in the laboratory. First, all components of the mix were weighed and placed in the mixer pan and mixed for two minutes. Water, together with half the amount of HRWA, was added slowly over four minutes, followed by one minute of mixing. The second half of HRWA was then added over 30 seconds, followed by another minute of mixing. The accelerator was then added over the next minute, followed by another minute of mixing, or until the material became a thick paste. Fibres were then added to the mix slowly over two minutes, and then mixed for a minute, or until the fibres were well dispersed. The total time for this process never exceeded 35 minutes. Once the fibres were visually found to be well dispersed, the UHPFRC mix was removed from the mixers and tested for flow. The ASTM C1437 (2013) was used to check the flow of each batch, and it was found that each batch exceeded the capacity of the flow table.

Specimens were then cast using a vibratory table, which vibrated at $60 \mathrm{~Hz}$ with adjustable amplitudes. Since the used mix had a high flow, the vibrations were kept to a minimum to avoid separation of steel fibres. The cylinders were next cast in three to four lifts in $150 \mathrm{~mm}$ [5.90 in.] plastic moulds. The casting for all specimens was completed within 30 minutes from its removal from the mixer.

Subsequent to completion of casting, specimens were covered in a heavy plastic sheet and left to set for 48 hours before being removed from the mould. They were then placed in a steam cure box. The curing process began at room temperature and ambient relative humidity (RH), and was brought to the target levels of $90{ }^{\circ} \mathrm{C}$ $\left[194^{\circ} \mathrm{F}\right]$ and $95 \%$ RH typically within 90 minutes. The total curing time was 48 hours, after which specimens were removed from the steam cure box and placed back in laboratory conditions to cool down. 


\subsection{Sample preparation}

Before cutting the test samples from the cylinders, a testing matrix was constructed to randomize sample locations (zones) for the further investigation. The cylinders were cut into three zones (top, middle, bottom) to allow for analysis on the fibre distribution and orientation, and to differentiate fracture properties as a function of cylinder height. The slice thicknesses required for fracture tests are $25 \mathrm{~mm}$ [.984 in.] and $37.5 \mathrm{~mm}$ [1.48 in.], which lead to one $25 \mathrm{~mm}$ [.984 in.] and two $37.5 \mathrm{~mm}$ [1.48 in.] slices per each cylinder (Fig. 1). Table 2 shows the detailed matrix with randomized locations for all tests. Since two test samples are produced from each $25 \mathrm{~mm}$ [.984 in.] slice, there were four $37.5 \mathrm{~mm}$ [1.48 in.] samples and four $25 \mathrm{~mm}$ [.984 in.] samples created for each zone from all six cylinders. It should be noted that half the specimens were heat treated after the cutting in order to introduce additional factor to the analysis of the fracture energy.

To prepare the cylinders for cutting, $10 \mathrm{~mm}$ [.394 in.] slices from both ends of the cylinders were cut off using a diamond wet saw with a special clamping fixture to hold specimens and to ensure parallel cut planes. Specimens were then cut from the top down as prescribed by the test matrix shown in Table 2 . Once the slices were obtained from the cylinders, fine cutting was done to geometrically prepare each sample for their appropriate testing.

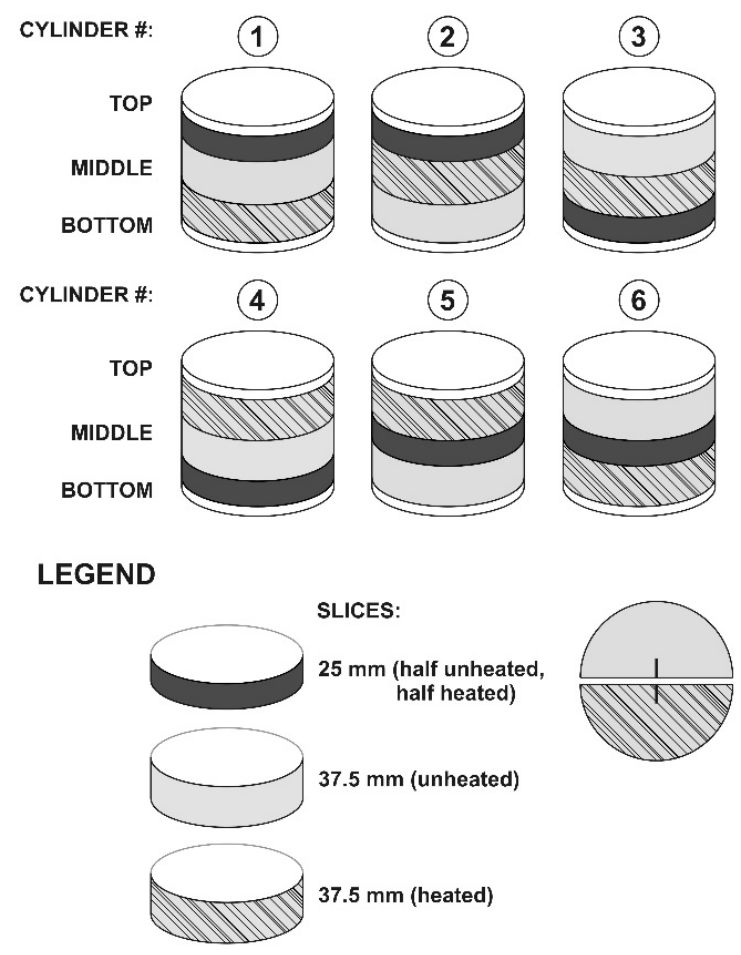

Fig. 1. UHPFRC specimen cutting sequence

Three separate experimental approaches were undertaken in order to investigate the influence of sample preparation and zone location on fibre orientation. The first approach evaluated the density of the UHPFRC at different locations within the cylinder. The densities were calculated by measuring masses and dimensions of all samples from different locations. The second approach observed the differences in fracture energy at different locations of the casted specimens, both in tension and compression. Fracture energies were determined from the Disc-Compact Tension Test (DCT) for tension $(37.5 \mathrm{~mm}$ [1.48 in.] specimens) and the Semi-Circular Bending Test (SCB) for compression (25 mm [.984 in.] specimens). Lastly, X-ray tomography scans were obtained to qualitatively and quantitatively capture the differences in the orientation and distribution of fibres within three different locations, i.e. top, middle and bottom.

Table 2. Test matrix for cylinders: $1=$ one non-heat treated sample, $1^{*}=$ one heat treated sample

\begin{tabular}{|c|c|c|c|}
\hline Cylinder & Location & $\begin{array}{c}25 \mathrm{~mm} \\
\text { [.984 in.] } \\
\text { slices }\end{array}$ & $\begin{array}{c}37.5 \mathrm{~mm} \\
{[1.48 \text { in. }]} \\
\text { slices }\end{array}$ \\
\hline \multirow{3}{*}{1} & Top & $1,1 *$ & \\
\hline & Middle & & 1 \\
\hline & Bottom & & $1 *$ \\
\hline \multirow{3}{*}{2} & Top & $1,1^{*}$ & \\
\hline & Middle & & $1 *$ \\
\hline & Bottom & & 1 \\
\hline \multirow{3}{*}{3} & Top & & 1 \\
\hline & Middle & & $1 *$ \\
\hline & Bottom & $1,1^{*}$ & \\
\hline \multirow{3}{*}{4} & Top & & $1 *$ \\
\hline & Middle & & 1 \\
\hline & Bottom & $1,1 *$ & \\
\hline \multirow{3}{*}{5} & Top & & $1 *$ \\
\hline & Middle & $1,1 *$ & \\
\hline & Bottom & & 1 \\
\hline \multirow{3}{*}{6} & Top & & 1 \\
\hline & Middle & $1,1^{*}$ & \\
\hline & Bottom & & $1 *$ \\
\hline
\end{tabular}

As mentioned before, half the specimens designated for each test were heat treated in the ignition oven. This treatment created another factor in studying fracture properties of the UHPFRC specimens and in particular allowed to measure their residual properties. Specimens assigned for the heat treatment were heated from room temperature to the target temperature of $600{ }^{\circ} \mathrm{C}\left[1112^{\circ} \mathrm{F}\right]$ at the heating rate of $5^{\circ} \mathrm{C}\left[41^{\circ} \mathrm{F}\right] /$ minute. Once the specimen reached the target temperature, they were held at that temperature for 6 hours. After that period, specimens were removed from the oven and cooled at room temperature before testing.

\subsection{Fracture testing}

Fracture testing for both SCB and DCT were performed in a servo-hydraulic $100-\mathrm{kN}$ load frame with a closedloop computerized data acquisition system. All tests were performed at ambient temperature and within 3 weeks after specimen preparation.

The DCT test was originally developed for testing fracture properties of metals but has never been used to test UHPFRC. In this study, the fracture energy was determined using a $37.5 \mathrm{~mm}$ [1.48 in.] thick specimens as opposed to $50 \mathrm{~mm}$ [1.968 in.] asphalt specimens. Thinner 
samples are sufficient for testing UHPFRC since such a concrete has significantly finer aggregate structure as compared to the asphalt concrete. DCT specimens were cut to a disc-like geometry with a pre-crack and two pullpoints as shown in Figure 2.

a)

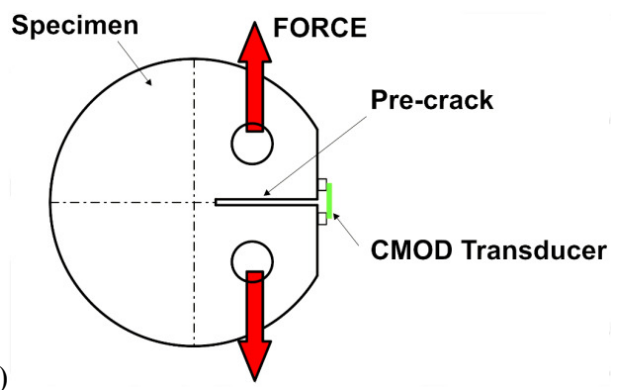

b)

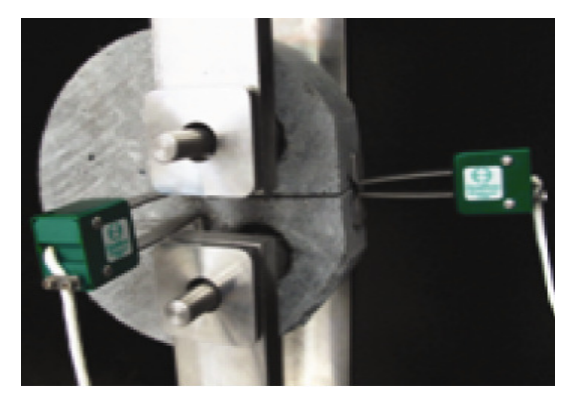

Fig. 2. Disc Compact Tension test (DCT): a) DCT schematic; b) DCT picture (with additional CMOD mounted on the front face)

The SCB is another test used to evaluate fracture properties of different materials but similar to the DCT test, was yet to be used on the UHPFRC specimens. In this study, slices were cut to thickness of $25 \mathrm{~mm}$ [.984 in.], and then cut diametrically to create two semicircular specimens. A pre-crack notch was then created in the middle of the specimen similar to the geometry shown in Figure 3.

Before testing, each specimen was accurately measured to properly calculate the fracture area once the testing was finalized. At the beginning of a test, a crack mouth opening displacement (CMOD) sensor was placed on the pre-crack and $0.35 \mathrm{kN}$ seating load was applied to the specimen. Once the load reached $0.35 \mathrm{kN}$, the actual test started in the closed-loop mode, i.e. the load is constantly adjusted in order to maintain a constant CMOD rate. The CMOD rates for DCT and SCB were $1 \mathrm{~mm}$ [.039 in. $] / \mathrm{min}$ and $0.3 \mathrm{~mm}[.012 \mathrm{in}.] / \mathrm{min}$, respectively. This rate continued until the load fell below $0.5 \mathrm{kN}$ in the softening region of the fracture curve or if the CMOD opened beyond the working range of the gauge (approximately $7 \mathrm{~mm}[.275 \mathrm{in}$.$] ). The fracture energy G_{f}$ was then computed for both DCT and SCB tests using Eqn:

$$
G_{f}=\int \frac{P}{A_{\text {lig }}} d u
$$

where: $G_{f}-$ fracture energy $\left(\mathrm{J} / \mathrm{m}^{2}\right) ; P-\operatorname{load}(\mathrm{kN})$; $u$-CMOD opening (m); $A_{\text {lig }}-$ area of ligament $\left(\mathrm{m}^{2}\right)$.
In order to calculate the total fracture energy, the load-CMOD curves were extrapolated to obtain energy beyond the end of the test, i.e. between last recorded load value and zero force. After preliminary trials, it was determined that an exponential equation provides the best extrapolation fit.

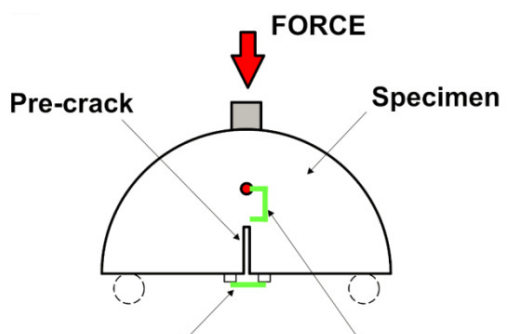

a)

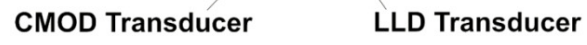

b)

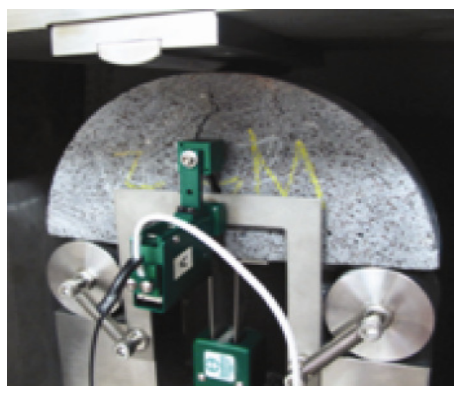

Fig. 3. Semi-Circular Bending test (SCB): a) SCB schematic; b) SCB Picture

\section{Results and discussion}

To investigate the impact of fibre orientation in the UHPFRC specimens as the function of zone location within a cylinder, three aforementioned approaches were employed. The results from each approach are presented in next three paragraphs.

\subsection{Density distribution}

It was hypothesized that distribution of fibres along the height of the cast cylinders is not uniform, which results in varying quantity of fibres and/or differing fibre orientations between cylinder locations. The bulk density approach seemed to be very practical as it calculated only the density at different locations of the specimens. The density results are shown in Figure 4. Although there is a

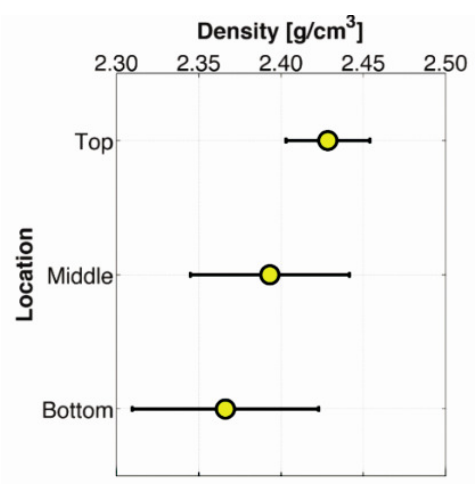

Fig. 4. Density for each location; circle markers indicate the mean; error bars extend one standard deviation 
linear trend showing a decrease in average densities with height, statistical analysis of the means showed the location factor was insignificant. Since the statistical analysis showed no significance, the density calculations may not have captured the potential differences in fibre amounts along the cylinder height. While steel fibres were only $2 \%$ by volume of the mix, the differences in mass between sections is likely difficult to quantify.

\subsection{Fracture energy}

\subsubsection{Disc-Compact Tension Test (DCT)}

All specimens from bottom zones and the majority of middle zone specimens failed to test properly in the DCT configuration by initiating and propagating cracks beyond the pre-crack. Figure 5a shows a DCT specimen from the top cylinder zone that cracked properly with the crack initiation at the tip of the pre-crack. Alternatively, a bottom specimen in Figure 5b failed to test properly in the DCT since the crack initiated beyond the pre-crack. The energies of the failing specimens were not taken into account for analysis. It was hypothesized at this point that fibres settled during casting and oriented in a non-random pattern creating weak paths in the specimens cut from the bottom as well as some middle zones. The ability to test the same specimen at different locations is a significant advantage to using the DCT experiment setup as opposed to traditional tensile testing setups.

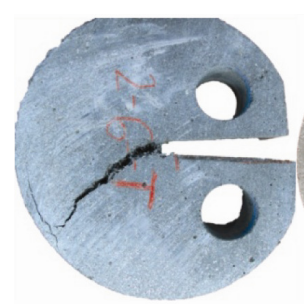

a)

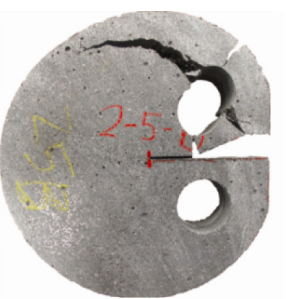

b)
Fig. 5. Disc-Compact Tension Test (DCT): a) Proper DCT test; b) Failed DCT test

The summary of the DCT results from the top locations is shown in Figure 6a. It is evident that the heat treatment played a statistically significant role in fracture energy. The main difference between these specimens was the post-peak region: non-heat treated specimen exhibited much slower softening behaviour, which resulted in double the total fracture energy. The prolonged exposure to severe heat made the UHPCFR more brittle, including the fibres, which were audibly breaking during the post-peak period. These results are more detrimental than other studies conducted previously on the tensile strength of heat-treated UHPFRC specimens. For example, in the study by Vejmelková et al. (2010) it was found that high-density glass fibre reinforced cement composite delivers $33 \%$ of its nominal tensile strength after heating specimens to $600{ }^{\circ} \mathrm{C}$ $\left[1112^{\circ} \mathrm{F}\right]$. The results presented herein suggest that this UHPCFR delivers on average only $36 \%$ of its nominal tensile fracture strength after extreme heating treatment. This difference suggests that heating the specimens faster and for a longer duration can significantly weaken the material. It also suggests that the DCT test may be more sensitive in analysing concrete for tensile strength as compared to the direct tensile test.

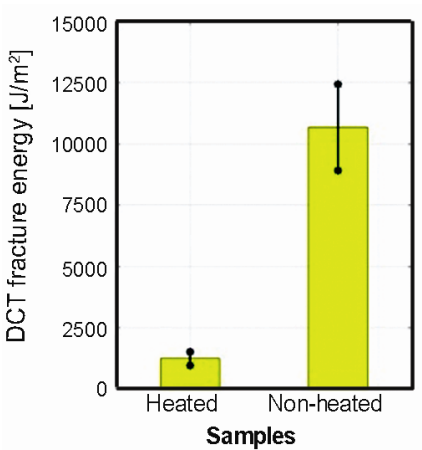

a)

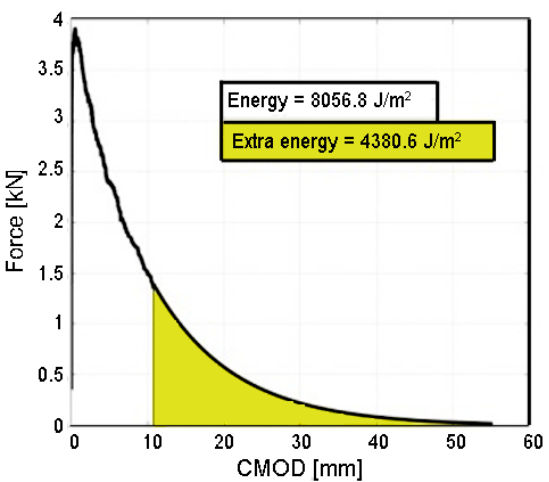

b)

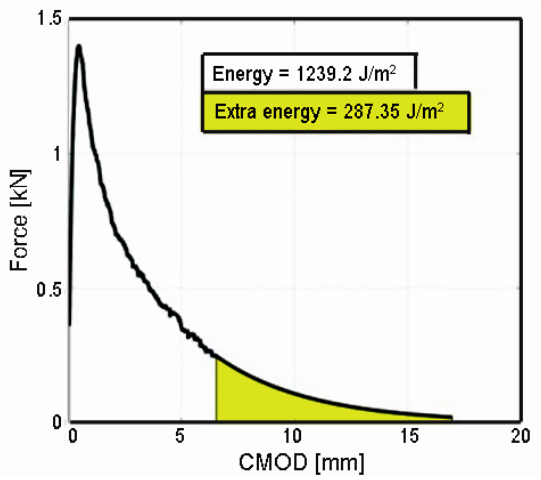

Fig. 6. Disc-Compact Tension Test (DCT) results: a) The total fracture energy for DCT specimens cut from zones at the top of cylinders, star markers indicate the value range, the bar presents the mean value; b) Example of Load-CMOD curve for unheated DCT specimens; c) Example of Load-CMOD curve for heat treated DCT specimens

\subsubsection{Semi-Circular Bending Test (SCB)}

Similar to DCT results, all specimens tested from zones at the bottom of cylinders failed to test properly in the SCB configuration. Most of these failures occurred by crack initiation above one of the roller supports rather than at the tip of the pre-crack. Figure 7a shows a properly tested SCB specimen with a crack propagating up from the pre-crack, whereas Figure $7 \mathrm{~b}$ shows an improper test where an abrupt fracture occurred at the left roller. It should also be noted that the visual observation of all samples similar to the one shown in Figure $7 \mathrm{~b}$ resulted in discovery that most of steel 
fibres were aligned with the fracture path, which lead to the crack initiation in the weak spot that was lacking the bridging reinforcement of steel fibres.

a)

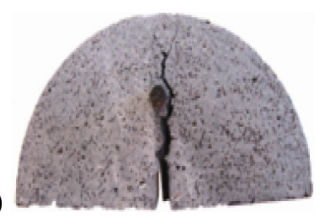

b)

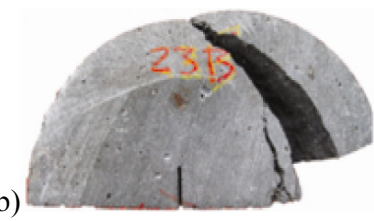

Fig. 7. Semi-Circular Bending Test (SCB): a) Proper SCB test; b) Failed SCB test

The results from the SCB testing are presented in Figure 8a. As compared to the DCT results, more SCB specimens from middle locations tested correctly and were included in the analysis. Similar to the DCT results though, the post-peak energy as well as peak load for the heat-treated specimens was significantly lower than for the non-heat treated specimens as seen in Figures $8 \mathrm{~b}$ and 7c. An analysis of variance indicated that heat-treatment was a significant factor in fracture energy and that nonheated specimens cut from zones in the middle of cylinders demonstrated higher fracture energy than the specimens from the top zone.

\subsection{X-ray CT}

Results from density and fracture energy investigations indicated that there is a variation between the three zones of the UHPFRC cylinders. As the final attempt to verify fibre orientation within different cylinder zones, X-ray CT scans were performed using an Xradia (C) MicroXCT 400 device. Spatial quantitative analysis was done on the orientation of fibres with respect to the horizontal and vertical planes. In order to conduct X-ray scans, $25-\mathrm{mm}$ diameter cylinders were drilled from the same location of both a top- and bottom-zone DCT specimen and run through the X-ray device. Multiple 2D images were stacked together and processed to create 3D representations of internal fibre structures shown in Figure 9. The qualitative evaluation of fibre structures in Figure 9 shows that fibres in the bottom-zone specimen (on the right) are favouring one direction and exhibit less random orientation than the top-zone sample (on the left). However, such an evaluation is fairly subjective so more robust procedure was employed in the next analysis step.

In order to quantify the fibre orientation in space, 3D X-ray images were analysed using digital image processing software. Raw stacks of horizontal 2D slices from the X-ray device were manipulated using combination of thresholding and morphological operations. In the results, all identified fibres were saved as separate objects and different geometrical properties were calculated for each object. In particular, the following two parameters are used in this study: Phi angle and Theta angle. The directions of both angles are defined in Fig. 10. The Phi angle provides information on the vertical orientation of an object and can vary between $-90^{\circ}$ and $+90^{\circ}$ with respect to the horizontal plane (xy-plane). The Theta angle, on the other hand, measures the orientation of an object in the horizontal plane and ranges from $0^{\circ}$ to $360^{\circ}$ starting from the $\mathrm{x}$-axis.

a)
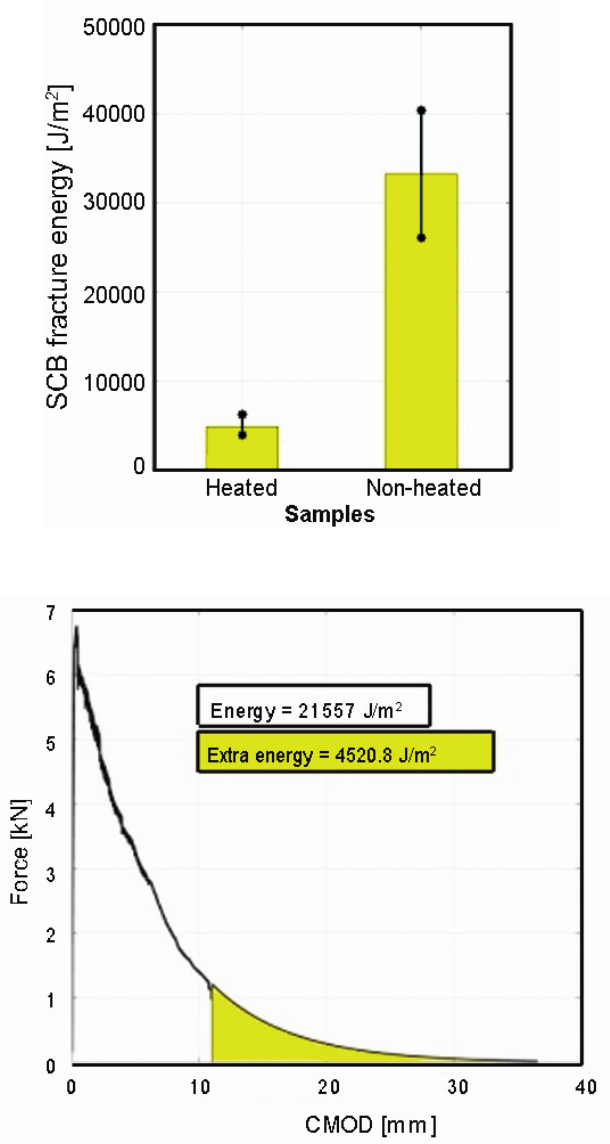

b)

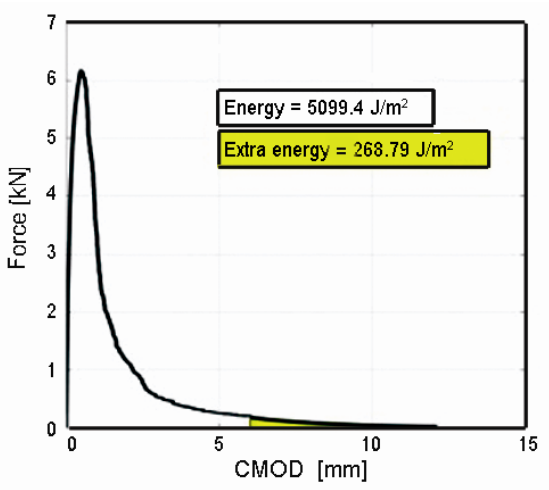

c)

Fig. 8. Results from the SCB testing: a) The total fracture energy for SCB specimens cut from zones at the top and middle of cylinders, star markers indicate the value range, the bar presents the mean value; b) Example of Load-CMOD curve for untreated SCB specimens; c) Example of Load-CMOD curve for heat treated SCB specimens 


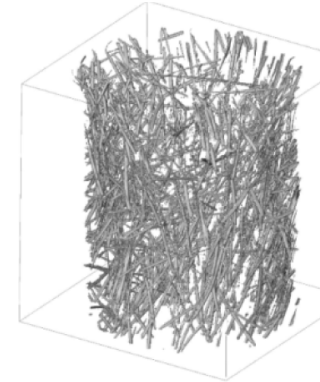

a)

Fig. 9. 3-D X-rays: a) 3-D X-rays taken from top sample; b) 3-D $\mathrm{X}$-rays taken from bottom sample

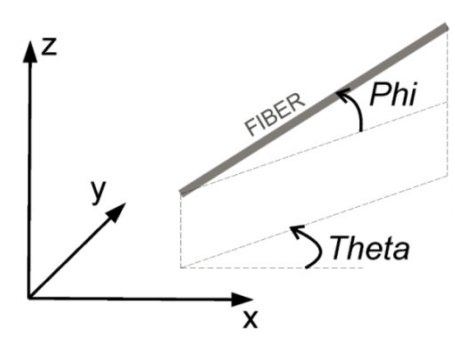

Fig. 10. Definition of Phi and Theta angles

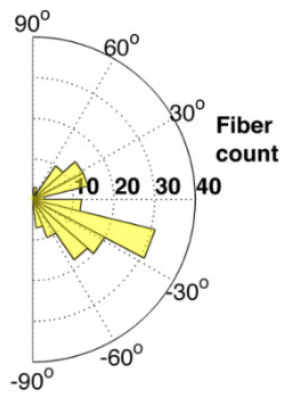

a)

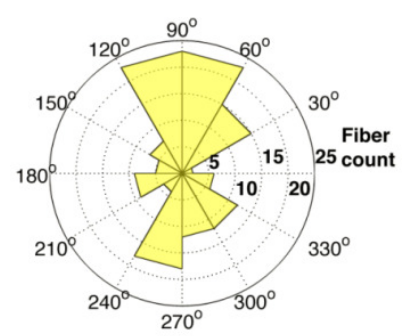

c)

d)

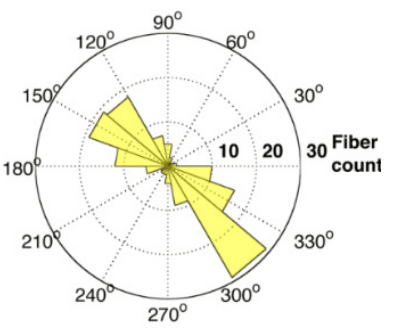

Fig. 11. Distributions of Phi $(a, b)$ and Theta $(c, d)$ angles for fibre orientations in specimens cut from the top zone (a, c) and the bottom zone $(b, d)$

Figure 11 shows the distribution of fibre angles for both specimens (top-zone and bottom-zone). Several observations can be made based on Figure 11:

- The Phi angle distribution for top-zone specimen is more spread, which indicates a more random fibre orientation in the vertical direction between $-75^{\circ}$ and $75^{\circ}$. There are also very few fibres oriented in the horizontal direction $\left(0^{\circ}\right)$.
- The Phi angle distribution for the bottom-zone specimen shows a distinct peak close to $-15^{\circ}$, which confirms the visual observation drawn from Figure 9 and suggests that fibres were consolidated flat and aligned along the horizontal plane.

- The Theta angle distribution for the top-zone specimen shows a wide spread of values, which again indicates a more random fibre orientation in this location.

-Finally, the Theta angle distribution for bottom-zone specimen shows one distinct direction, which agrees with Figure 9 and the Phi angle observations from this location.

In the summary, quantitative analysis of the 3D Xray scans confirmed that fibre orientations in the top-zone specimen are more random and angle ranges in both directions are wider spread. On the other hand, the bottomzone specimen comprises unfavourable orientations in both directions, which is a potential cause for the specimen failures to test properly in the DCT and SCB fracture experiments.

\section{Conclusions}

This study presents the effects of a standard laboratory preparation on the fibre dispersion and orientation in the Ultra-High Performance Fibre Reinforced Concrete (UHPFRC). Specimens were prepared using a special premix combined with steel fibres. As an additional factor, half of the specimens were heat-treated for 6 hours at $600^{\circ} \mathrm{C}\left[1112^{\circ} \mathrm{F}\right] . \mathrm{SCB}$ and DCT tests were then run on the specimens to determine UHPFRC fracture energies in the compressive and tensile modes. Lastly X-ray CT was used to qualitatively capture the fibre orientation within different locations of the cast cylinder. The following conclusions can be made based on observations of this study:

1. Density calculations showed no statistical difference of fibre dispersion within different locations of the specimens.

2. Specimens located at the bottom of the cylinders failed to test adequately in the SCB, while both bottom and most middle specimens tested incorrectly in the DCT. These failures trigger the hypothesis that fiber orientation is changing along the depth of the cast cylinders.

3. Heat treated specimens in both compression and tension conditions had significantly smaller fracture energy than non-heated specimens and the difference was more distinct in tension mode. The average percent difference between untreated and heated specimens was found to be on average $88 \%$ in tension and $83 \%$ in compression.

4. X-ray tomography analysis confirmed the hypothesis that fiber orientation in top- and bottom-zone specimens differ significantly. Distributions of $P h i$ and Theta angles showed clearly that top specimens have more random fiber orientations whereas bottom samples are oriented flat and favor one specific direction in the horizontal plane. Such an orientation is a potential cause for the failure to test properly in the DCT and SCB fracture experiments. 
It is concluded that a special attention should be made while preparing the UHPFRC samples in the laboratory conditions in order to ensure homogeneity of the material and to determine representative properties of the actual material used in a structure.

\section{Acknowledgments}

The authors would like to thank the Department of Homeland Security, specifically the Transportation Security Center of Excellence (NTSCOE) at the University of Connecticut for partially funding of this study. The Authors are grateful to Brian Burke, Tyler Swanson, and Russell Dutta for their help with specimen preparation. The authors would also like to thank the University of Connecticut Fuel Cell Center for help with X-ray tomography. Authors are also thankful to Lafarge for materials provided for this study. The results and opinions presented in this paper are those of the authors and do not necessarily reflect those of involved agencies.

\section{References}

ASTM C1437. Standard test method for flow of hydraulic cement mortar. 2013. http://dx.doi.org/10.1520/C1437

Barnett, S.; Lataste, J.; Parry, T.; Millard, S.; Soutsos, M. 2010. Assessment of fibre orientation in Ultra High Performance Fibre Reinforced Concrete and its effect on flexural strength, Materials and Structures 43(7): 1009-1023. http://dx.doi.org/10.1617/s11527-009-9562-3

Barris, C.; Torres, L.; Miàs, C.; Vilanova, I. 2012. Design of FRP reinforced concrete beams for serviceability requirements, Journal of Civil Engineering and Management 18(6): 843-857.

http://dx.doi.org/10.3846/13923730.2012.720934

Chanvillard, G.; Rigaud, S. 2003. Complete characterization of tensile properties of DUCTAL UHP-FRC according to the French recommendations, Fourth International Workshop on High Performance Fiber Reinforced Cement Composites (HPFRCC4), 16-18 June, 2003, Ann Arbor, Michigan, USA, 21-34.

Corinaldesi, V.; Moriconi, G. 2012. Mechanical and thermal evaluation of ultra-high performance fiber reinforced concretes for engineering applications, Construction and Building Materials 26(1): 289-294. http://dx.doi.org/10.1016/j.conbuildmat.2011.06.023

Dai, Q.; Ng, K.; Zhou, J.; Kreiger, E.; Ahlborn, T. 2012. Damage investigation of single-edge notched beam tests with normal strength concrete and ultra-high performance concrete specimens using acoustic emission techniques, Construction and Building Materials 31: 231-242. http://dx.doi.org/10.1016/j.conbuildmat.2011.12.080

Ferrara, L.; Ozyurt, N.; Prisco, M. 2011. High mechanical performance of fibre reinforced cementitious composites: the role of "casting-flow induced" fibre orientation, Materials and Structures 44(1): 109-128. http://dx.doi.org/10.1617/s11527-010-9613-9

Graybeal, B. A.; Hartmann, J. L. 2003. Strength and durability of Ultra High Performance Concrete, in The Concrete Bridge Conference, 2003, Portland Cement Association, Orlando. $20 \mathrm{p}$.
Graybeal, B. A. 2007. Comparative behavior of ultra-high performance fiber-reinforced concrete, ACI Material Journal 104(2): 146-15.

Graybeal, B. A. 2006. Material property characterization of ultra-high performance concrete, Report No. FHWAHRT-06-103, Federal Highway Administration, Washington, D. C. $186 \mathrm{p}$.

Gribniak, V.; Kaklauskas, G.; Bacinskas, D.; Sung, W.-P.; Sokolov, A.; Ulbinas, D. 2011. Investigation of shrinkage of concrete mixtures used for bridge construction in Lithuania, The Baltic Journal of Road and Bridge Engineering 6(2): 77-83.

http://dx.doi.org/10.3846/bjrbe.2011.10

Grinys, A.; Sivilevicius, H.; Pupeikis, D.; Ivanauskas, E. 2013. Fracture of concrete containing crumb rubber, Journal of Civil Engineering and Management 19(3): 447-455. http://dx.doi.org/10.3846/13923730.2013.782335

Hassan, A.; Jones, S.; Mahmud, G. 2012. Experimental test methods to determine the uniaxial tensile and compressive behaviour of Ultra High Performance Fibre Reinforced Concrete (UHPFRC), Construction and Building Materials 37 : 874-882.

http://dx.doi.org/10.1016/j.conbuildmat.2012.04.030

Islam, N.; Zain, M. F. M.; Jamil, M. 2012. Prediction of strength and slump of rice husk ash incorporated highperformance concrete, Journal of Civil Engineering and Management 18(3): 310-317.

http://dx.doi.org/10.3846/13923730.2012.698890

Kang, S.; Lee, B.; Kim, J.; Kim, Y. 2011. The effect of fibre distribution characteristics on the flexural strength of steel fibre-reinforced ultra-high strength concrete, Construction and Building Materials 25(5): 2450-2457. http://dx.doi.org/10.1016/j.conbuildmat.2010.11.057

Kim, D.; Park, S.; Ryu, G.; Koh, K. 2011. Comparative flexural behaviour of hybrid ultra-high performance fiber reinforced concrete with different macro fibers, Construction and Building Materials 25(11): 4144-4155. http://dx.doi.org/10.1016/j.conbuildmat.2011.04.051

Lee, C.; Kim, H. 2010. Orientation factor and number of fibers at failure plane in ring-type steel fiber reinforced concrete, Cement and Concrete Research 40(5): 810-819. http://dx.doi.org/10.1016/j.cemconres.2009.11.009

Pajak, M.; Ponikiewski, T.; 2013. Flexural behavior of selfcompacting concrete reinforced with different types of steel fibers, Construction and Building Materials 47: 397408. http://dx.doi.org/10.1016/j.conbuildmat.2013.05.072

Vejmelková, E.; Konvalinka, P.; Padevět, P.; Černý, R. 2010. Thermophysical and mechanical properties of fiber reinforced composite material subjected to high temperatures, Journal of Civil Engineering and Management 16(3): 395-400. http://dx.doi.org/10.3846/jcem.2010.45

Wille, K.; Kim, D.; Naaman, A. E. 2010. Strain-hardening UHP-FRC with low fiber contents, RILEM-Materials and Structures. http://dx.doi.org/10.1614/S11527-101-9650-4

Yao, W; Li, J.; Wu, K. 2003. Mechanical properties of hybrid fiber-reinforced concrete at low fiber volume fraction, Cement and Concrete Research 33(1): 27-30. http://dx.doi.org/10.1016/S0008-8846(02)00913-4

Zollo, F. 1997. Fiber-reinforced concrete: an overview after 30 years of development, Cement Concrete Composites 19(2): 107-122. http://dx.doi.org/10.1016/S0958-9465(96)00046-7 
Adam ZOFKA. PhD, Eng, Professor at the Road and Bridge Research Institute (IBDiM) in Poland. He received his PhD degree at the University of Minnesota in 2007 and then worked as an Assistant Professor at the University of Connecticut (2007-2012). He authored and co-authored close to 100 scientific publications. His research interest includes pavement technology, pavement maintenance and pavement evaluation.

Miglė PALIUKAITÉ. PhD student, Junior Scientist at Road Research Institute in Vilnius, Lithuania. She received her Master's degree at Road Department at Vilnius Gediminas Technical University in 2010. Research interest: bituminous binders, physical-chemical analysis of bitumen, rheological characterisation of bitumen, durability assessment of bituminous binders.

Audrius VAITKUS. PhD, Director of Road Research Institute in Vilnius, Lithuania. He received his PhD degree at Vilnius Gediminas Technical University in 2007. Research interest: pavement structure design, performance-based characteristics of materials, pavement structure performance, pavement surface characteristics.

Dominika MALISZEWSKA. MSc, Eng, Pavement Technology Division at the Road and Bridge Research Institute (IBDiM) in Poland. She received her Master's degree at Civil Engineering Department at Warsaw University of Technology. Research interest: bituminous mixtures, pavement design, research and technology.

Ramandeep JOSEN. MSc, Eng, Pavement Management Engineer at Fay, Spofford \& Thorndike, Inc. in Massachusetts, USA. He received his Master's degree at the Civil and Environmental Engineering Department at the University of Connecticut in 2012. Research interest: pavement management and evaluation, artificial intelligence, mechanical characterization of cementitious materials.

Alexander BERNIER. MSc, Eng, Civil Designer at Stantec Consulting in New York, USA. He received his Master's degree at the Civil and Environmental Engineering Department at the University of Connecticut in 2012. Research interest: airfield pavement design and evaluation, computer-aided design, mechanical characterization of cementitious materials. 